
About IJMA [last updated July, $\left.1^{\text {st }}, 2021\right]$

$\checkmark$ International Journal of Medical Arts is the Official Journal of the Damietta Faculty of Medicine, AlAzhar University, Egypt

$\checkmark$ It is an International, Open Access, Double-blind, Peer-reviewed Journal

$\checkmark$ Published four times a year

$\checkmark$ The First Issue was published in July 2019

$\checkmark$ Published under the following license: Creative Commons Attribution-ShareAlike 4.0 International Public License (CC BY-SA 4.0). It had updated from the Creative Commons license [CC BY] in volume 2, Issue 4, October 2020 About IJMA

$\checkmark$ The Egyptian Knowledge Bank hosts the web site of IJMA

$\checkmark$ The Egyptian Knowledge Bank supports IJMA

$\checkmark$ IJMA follows the regulations of the International Committee of Medical Journal Editors

$\checkmark$ IJMA is indexed in the "Directory of Open Access Journals" [15 January 2021].

$\checkmark$ IJMA is indexed in JGate [29-6-2021]

$\checkmark$ IJMA is a member of the International Society of Managing and Technical Editors

$\checkmark$ Listed in "Index Copernicus", "Publons", "Academic resource index [ResearchBib]", "Electronics journal library", "Eurasian Scientific Journal Index", and "Citefactor"

$\checkmark$ IJMA introduced to the search engine [BASE] through DOAJ
Click image to reach the page

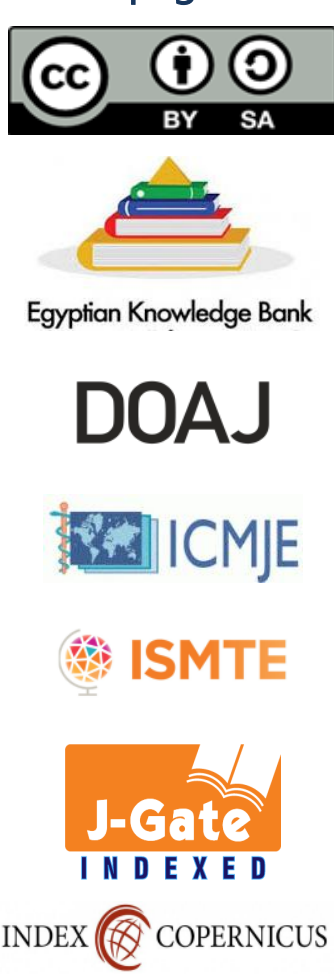

publons

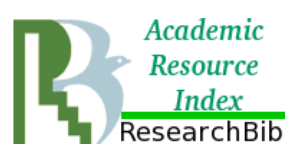

\section{EZ3 \\ .}

ESJII

CiteFactor

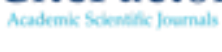

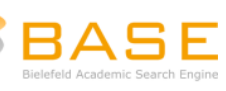




Available online at Journal Website
https://ijma.journals.ekb.eg/
Main subject [Obstetrics and Gynecology]

Original Article

\title{
Nitric Oxide Donor Administration For improvement of Uterine Blood Flow in Unexplained Recurrent Pregnancy Loss
}

\author{
Mazen A. El-Zahry \\ Department of Obstetrics and Gynecology, Faculty of Medicine, Al-Azhar University, Egypt. \\ Email: mazenobgyn@gmail.com
}

Submission date: May 01, 2021; Revision date: June 20, 2021; Acceptance date: June 30, 2021

DOI: 10.21608/ijma.2021.182971

DOAJ

\section{ABSTRACT}

Background: Recurrent pregnancy loss is still a challenging obstetric condition. It linked to impaired uterine blood, and vasodilators seem to prevent recurrent pregnancy loss.

The aim of the work: The current study aimed to compare between investigate the Doppler uterine artery indices in females with recurrent pregnancy loss [unexplained]. It also aimed to study the effect of intravaginal isosorbide mononitrate, on the pattern of uterine blood flow.

Materials and Methods: This observational, nested case control study had been completed at Al-Azhar University Hospitals. Two groups of females [each 50 females] were studied. The control group [females with no previous pregnancy loss and have a viable child or more]. The study group [females with history of unexplained recurrent pregnancy loss]. Vaginal color Doppler ultrasound was done to assess pulsation and resistance indices of uterine arteries in the mid-luteal phase of the cycle. Then, $20 \mathrm{mg}$ of isosorbide mononitrate was applied vaginally and measurement of the vascular indices were registered after two hours again. Both groups were compared and the effect of isosorbide mononitrate on the uterine artery vascular indices the study group was documented.

Results: Higher uterine artery resistance and pulsation indices are noticed in females with recurrent pregnancy. A significant reduction in these indices was found after vaginal application of Isosorbide mononitrate. Both groups were comparable regarding patient demographics. Doppler indices were significantly lower in control than study group. The endometrial thickness was negatively correlated with right $\mathrm{RI}$ and left $\mathrm{PI}(r=-0.328,-0.342, p=0.039$ and 0.031 , respectively).

Conclusion: Poor uterine perfusion is associated with spontaneous abortion. The vaginal application of isosorbide mononitrate, nitric oxide donor could be an effective treatment for the correction of uterine vasculature in patients with recurrent pregnancy loss.

Keywords: Isosorbide mononitrate; Recurrent Pregnancy Loss; Pulsatility Index; Uterine Artery; Uterine Receptivity.

This is an open-access article registered under the Creative Commons, ShareAlike 4.0 International license [CC BY-SA 4.0] [https://creativecommons.org/licenses/by-sa/4.0/legalcode.

Citation: El-Zahry MA. Nitric Oxide Donor Administration For improvement of Uterine Blood Flow in Unexplained Recurrent Pregnancy Loss. IJMA 2021; 3 [3] July-September: 1525-1529. [DOI: 10.21608/ijma.2021.182971].

* Main subject and any subcategories have been classified according to the research topic. 


\section{INTRODUCTION}

Miscarriage is the commonest complication of pregnancy [1]. Early pregnancy loss is defined as loss of a pregnancy before viability [ $<20$ weeks of gestation] or [with a fetal weight of $<500 \mathrm{~g}$ ]. The condition is reported in about $5 \%$ of couples, and about $40 \%$ of cases of recurrent pregnancy loss [RPL] have no explanation in spite of endocrine, chromosomal, serologic and anatomic assessment [2].

The success to maintain an early pregnancy and implantation is affected by uterine perfusion, which regulates uterine receptivity [3].

During luteal phase, blood flow to uterine arteries is decreased to its least amount in the time coinciding with implantation window ${ }^{[4]}$.

Other investigators found that conception rate is inversely proportional to the pulsatility index $[\mathrm{PI}]$ and resistance index $[\mathrm{RI}]$ of uterine arteries $[2,5]$.

The Nobel Prize was awarded for Furchgott et al., regarding their effort in the field of nitric oxide [NO] research [6].

A significant role is found for vascular endothelial cells [L-arginine produces nitric oxide in Vivo] in the relaxation of vascular smooth muscle, the reduction of the in utero-placental resistance and increase in the blood flow of the uterine artery. Uterine perfusion is abnormal due to deficient production of endogenous $\mathrm{NO}$, which mainly participates in the pathogenesis, and is found to be a main cause of unexplained recurrent abortion [7].

A small number of studies have discussed the difference between females with recurrent pregnancy loss and normal fertility regarding the uterine artery indices and whether nitric oxide donors, may improve the impaired uterine blood flow to be of therapeutic value in these patients ${ }^{[8]}$.

\section{AIM OF THE STUDY}

The current study was designed to compare between females with and without recurrent pregnancy loss regarding uterine artery Doppler indices and to investigate the effect of isosorbide mononitrate on
Doppler indices in females with RPL.

\section{SUBJECTS AND METHODS}

One hundred females were recruited from the maternity units [Al-Azhar University Hospitals; AlHussein and Bab El-Sharia]. They were categorized into two equal groups according to their history of RPL. All females were screened and according to the history, female was nested into one of the two groups. The control group included females without previous abortion, who have one or more living child. The study group included non-pregnant females with three or more recurrent unexplained first and second trimester abortions before the age of viability [20 weeks]. Women in both groups were asked to attend during the 21-23 day of the cycle and were subjected to history taking, full clinical examination, mean arterial pressure measurement and vaginal ultrasound [US] to exclude any pelvic pathology. Pulsed color Doppler vaginal US was done to measure the resistance index [RI] and pulsation index $[\mathrm{PI}]$ of the uterine arteries.

Technique: The cervical canal was identified after obtaining a mid-sagittal section of the uterus. Paracervical vascular plexus was identified by moving the probe laterally until the uterine artery was recognized by the color Doppler at its cranial turning along the uterine body. The gate was adjusted to $2 \mathrm{~mm}$ with an angle of insonation less than 60 degrees, then three similar consecutive waveforms were obtained using power Doppler [Pw]. The PI and RI were recorded and the mean was calculated.

In the study group, $20 \mathrm{mg}$ tablet isosorbide mononitrate [IMN] was placed high in the vagina. The uterine artery $\mathrm{RI}$ and $\mathrm{PI}$ were measured again after two hours [the period of maximum effect of the drug as recommended by the manufacturer].

Ethical consideration: the study protocol was submitted and approved by the Local Research and Ethics Committee of Obstetrics and Gynecology [AlAzhar University]. The study aim was explained for each participant and their informed consent was obtained. The female privacy and confidentiality were guaranteed and the collected data were used only for the purpose of the research.

Statistical analysis: Descriptive statistics for 
measured variables were recorded and fed to an Excel sheet. Then transferred to statistical package for social science program, version 16 [SPSS Inc., USA]. Qualitative and quantitative groups were compared by Chi square and independent samples " $\mathrm{t}$ " tests, respectively. In addition, Doppler indices before and after interventions were compared by paired samples " $\mathrm{t}$ " test. The Pearson's correlation coefficient $(r)$ was calculated and $p$ value $<0.05$ was considered significant for explanation of the results.

\section{RESULTS}

In the current study, patients' age ranged between 18 and 37 years, and there was no significant difference between groups 1 and 2. Additionally, all patients in both groups had at least one viable child. Also, no significant difference was observed between both groups. The number of previous abortions in the study group ranged between 2 and 5 and the median was 4 [Table 1].

Regarding ultrasound data, there was a significant decrease of RI and PI on right and left uterine arteries in control compared to the study group. However, the endometrial thickness although higher among the study group, the difference was statistically nonsignificant [Table 2].

In the current work, endometrial thickness, there was negative significant correlation between endometrial thickness and each of the right RI and left PI. However, there was no other significant correlation [Table 3]. In the study group, after isosorbide mononitrate intravaginal application, there was a statistically significant decrease of the right and left PI and the right and left RI of the uterine artery [Table 4].

Table [1]: Patient characteristics of the studied groups

\begin{tabular}{|c|c|c|c|c|}
\hline \multicolumn{2}{|c|}{ Variable } & Group $1[n=50]$ & Group 2 [n=50] & $P$ value \\
\hline \multicolumn{2}{|c|}{ Age [years] [mean $\pm S D ;$ min.-max.] } & $27.5 \pm 4.64 ; 18-36$ & $29.07 \pm 3.92 ; 21-37$ & 0.08 \\
\hline \multirow{2}{*}{$\begin{array}{l}\text { Parity } \\
{[\mathrm{n}, \%]}\end{array}$} & Para 1 & $12[24.0 \%]$ & $16[32.0 \%]$ & \multirow[t]{2}{*}{0.50} \\
\hline & Para 2 & $38[76.0 \%]$ & $34[68.0 \%]$ & \\
\hline \multicolumn{2}{|c|}{ Previous abortions [mean $\pm S D ;$ min. -max.] [median] } & $4.14 \pm 0.70 ; 3-5[4]$ & & \\
\hline
\end{tabular}

Table [2]: Comparison between groups 1 and 2, regarding ultrasound findings

\begin{tabular}{|l|l|c|c|c|}
\hline Variable & Group 1 [n=50] & Group 2 [n=50] & P value \\
\hline Endometrial thickness [mm] & Right & $7.74 \pm 1.98[4-11]$ & $7.56 \pm 1.4[6-10]$ & 0.61 \\
\cline { 2 - 5 } $\begin{array}{l}\text { Uterine artery } \\
\text { RI }\end{array}$ & $0.88 \pm 0.09 ;[0.6-1.0]$ & $0.79 \pm 0.11 ; 0.64-1.0$ & $<0.001^{*}$ \\
\hline Uterine artery & $0.89 \pm 0.09 ;[0.7-1.0]$ & $0.82 \pm 0.11 ;[0.6-1.0]$ & $<0.001^{*}$ \\
\cline { 2 - 5 } & RI & $2.44 \pm 0.53[1.0-3.5]$ & $1.93 \pm 0.6[1.0-3.82]$ & $<0.001^{*}$ \\
\cline { 2 - 5 }
\end{tabular}

Table [3]: Correlation between Doppler Ultrasound Parameters of uterine Arteries and other measured variables among women of Group I [RPL Group] before administration of the drug.

\begin{tabular}{|c|c|c|c|c|c|c|c|c|}
\hline \multirow[b]{3}{*}{ Variables } & \multicolumn{4}{|c|}{ RI } & \multicolumn{4}{|c|}{ PI } \\
\hline & \multicolumn{2}{|c|}{ Right } & \multicolumn{2}{|c|}{ Left } & \multicolumn{2}{|c|}{ Right } & \multicolumn{2}{|c|}{ Left } \\
\hline & $r$ & $p$ & $r$ & $p$ & $r$ & $p$ & $r$ & $p$ \\
\hline Age & -0.112 & 0.490 & -0.169 & 0.299 & -0.100 & 0.538 & -0.237 & 0.141 \\
\hline Parity & 0.019 & 0.909 & -0.081 & 0.618 & 0.049 & 0.766 & -0.024 & 0.882 \\
\hline n. of previous abortions & -0.172 & 0.290 & -0.030 & 0.854 & -0.402 & 0.010 & -0.098 & 0.548 \\
\hline Endometrial thickness & -0.328 & $0.039^{*}$ & -0.310 & 0.051 & -0.271 & 0.091 & -0.342 & $0.031^{*}$ \\
\hline
\end{tabular}

Table [4]: ultrasound data before and after isosorbide mononitrate in the study group

\begin{tabular}{|l|l|c|c|c|}
\hline & & Before & After & $p$ \\
\hline \multirow{2}{*}{$\begin{array}{l}\text { Uterine artery } \\
\mathrm{PI}\end{array}$} & Right & $2.44 \pm 0.53[1.0-3.5]$ & $2.19 \pm 0.11[2.01-2.4]$ & $0.017^{*}$ \\
\cline { 2 - 5 } & Left & $2.62 \pm 1.16[0.75-3.48]$ & $2.29 \pm 0.14[2.08-2.58]$ & $0.009^{*}$ \\
\hline \multirow{2}{*}{$\begin{array}{l}\text { Uterine artery } \\
\mathrm{RI}\end{array}$} & Right & $0.88 \pm 0.09[0.6-1.0]$ & $0.75 \pm 0.04[0.69-0.85]$ & $0.011^{*}$ \\
\cline { 2 - 5 } & Left & $0.89 \pm 0.09[0.7-1.0]$ & $0.77 \pm 0.05[0.70-0.91]$ & $0.021^{*}$ \\
\hline
\end{tabular}




\section{DISCUSSION}

In the present study the control and the study groups were comparable, regarding the parity, maternal age and the endometrial thickness, but the resistance index and pulsatility index of the uterine arteries at 21-23 days of the cycle were significantly higher in females with RPL compared to normal fertile females. These results are in consistence with AbdelRazik et al. [9], who reported that unexplained recurrent abortion is associated with significantly higher uterine artery Doppler indices [RI and PI] and lower vascular, flow and vascular flow indices of the sub-endometrial layer.

In addition, these results come in agreement with Habara et al. [10], who investigated patients with RPL and found that uterine artery $\mathrm{PI}$ in women with antinuclear antibodies was significantly higher than women without. Among women without antinuclear antibodies, the PI was also significantly higher than the control group.

The same observations were discovered by Nakatsuka et al. [11] who found higher PI in recurrent abortion compared to a control group and recommended the use of pulsed Doppler ultrasound as a non-invasive tool for the evaluation of the uterine impedance.

In another study, recurrent pregnancy loss showed higher mid luteal PI compared to the values of the control group and there was no significant correlation between $\mathrm{PI}$ and the endometrial thickness, serum estradiol or maternal age [12]. Zhang et al. [13] found that the PI was significantly higher in the luteal phase of the menstrual cycle and the incidence of flow velocity waves was higher in women suffering from RPL than those in the control group.

In another study, during the second half of the menstrual cycle, females with RPL showed higher PI than normal females. Whatever the etiology of RPL [e.g., uterine anomalies, antiphospholipid syndrome and unexplained RPL], there was a significant increase of PI [14].

Nitric oxide generated in vivo from L-arginine is produced in excess during pregnancy, mainly in the vascular beds of the uterus and kidney and in the part of vessels not responding to vasoactive substances. It is important for smooth muscle relaxation and vasodilatation. It lowers blood pressure and improve blood supply to the feto-placental unit and maternal kidneys [8].

Impaired uterine perfusion due to deficient endogenous nitric oxide excretion, participating mainly in the pathogenesis, and is found to be a main cause of unexplained recurrent abortion [15]. Thus, the NO donors - which are drugs capable of releasing nitric oxide - affect the indices of the uterine artery in patients suffering from RPL was tested in this study by application of $20 \mathrm{mg}$ isosorbide mononitrate [IMN] vaginally during the mid-luteal phase. There was a significant decrease of $\mathrm{RI}$ and $\mathrm{Pl}$, indicating an increase of uterine blood flow. This encourages the use of isosorbide mononitrate in the early pregnancy in patients with RPL.

A previous study has used nitric oxide donors in different obstetric indications [e.g., intrapartum fetal distress related to uterine hyperactivity, to arrest premature labor, for pre-induction cervical ripening and for treatment of pre-eclampsia] [16].

IMN is sheep and cost effective drug. The toxicology and teratogenicity studies proved its safety during pregnancy, even at very high doses, and its use vaginally makes most of its action locally, avoiding the undesirable systemic effects ${ }^{[17]}$.

Results of the current work agree with the study of Abdel-Razik et al. [9], who reported that IMN significantly reduced the uterine artery and increased sub-endometrial blood flow indices $[p<0.001]$.

Another study by Mansour et al. [18] reported higher RI and PI of the uterine in cases of RPL than controls. They concluded that endometrial and/or subendometerial ischemia could play a role in the pathogenesis of RPL. The use of vascular enhancers is recommended in such cases. Finally, Yang et al. [19] reported that the uterine artery Doppler indices were significantly higher in RPL than controls. The use of vasodilators enhances the uterine artery Doppler indices.

Conclusion: There was a relationship between insufficient uterine perfusion. Isosorbide mononitrate, 
nitric oxide donor seems to be an effective treatment for correction of uterine vascular resistance in such patients. However, the small number of included patients and cross-sectional nature of the study, are limiting steps against globalization of the study results. Future large-scale studies are warranted.

\section{Financial and Non-Financial Relationships and Activities of Interest}

None

\section{REFERENCES}

1. Leon LJ, Solanky N, Stalman SE, Demetriou C, Abu-Amero S, Stanier P, Regan L, Moore GE. A new biological and clinical resource for research into pregnancy complications: The Baby Bio Bank. Placenta. 2016 Oct; 46:31-37. [DOI: 10.1016/j. placenta.2016.08.085].

2. Lazzarin N, Vaquero E, Exacoustos C, Romanini E, Amadio A, Arduini D. Midluteal phase Doppler assessment of uterine artery blood flow in nonpregnant women having a history of recurrent spontaneous abortions: correlation to different etiologies. Fertil Steril. 2007 Jun; 87[6]:1383-7. [DOI: 10.1016/ j.fertnstert.2006.11.049].

3. Wang T, Kang X, Zhao A, He L, Liu Z, Liu F. Low-dose aspirin improves endometrial receptivity in the midluteal phase in unexplained recurrent pregnancy loss. Int J Gynaecol Obstet. 2020 Jul; 150 [1]:77-82. [DOI: 10.1002/ijgo.13160].

4. Ali ME, Elswah HA, Hassan A. Doppler Study of Uterine and Ovarian Arteries in Cases of Unexplained Infertility [Case Control Study]. The Medical Journal of Cairo University 2018; 86: 3197-3202. [DOI: 10.21608/mjcu.2018.60287].

5. Khong SL, Kane SC, Brennecke SP, da Silva Costa F. Firsttrimester uterine artery Doppler analysis in the prediction of later pregnancy complications. Dis Markers. 2015; 2015: 679730. [DOI: 10.1155/2015/679730].

6. Ledingham MA, Thomson AJ, Greer IA, Norman JE. Nitric oxide in parturition. BJOG. 2000 May; 107 [5]: 581-93. [DOI: 10.1111/j.1471-0528.2000.tb13297.x].

7. Mohamed MF, Hassan FI, Mohammed ES. Comparison between uterine artery and sub-endometrial blood flow before and after Nitric oxide donors in women with recurrent miscarriage. Life Science Journal 2018; 15[2]: 8-11. [DOI: 10.7537/marslsj150218.02].

8. Rifat AJ. Doppler Ultrasound Screening of the Uterine Arteries as a Predictor for Early Miscarriage. International J Women's Health Reprod Sci. 2020; 8[1]: 79-84. [DOI: 10.15296/ijwhr. 2020.11].

9. Abdel-Razik M, El-Berry S, Mostafa A. The Effects of Nitric Oxide Donors on Uterine Artery and Sub-endometrial Blood Flow in Patients with Unexplained Recurrent Abortion. J
Reprod Infertil. 2014 Jul; 15 [3]:142-6. [PMID: 25202671].

10. Habara T, Nakatsuka M, Konishi H, Asagiri K, Noguchi S, Kudo T. Elevated blood flow resistance in uterine arteries of women with unexplained recurrent pregnancy loss. Hum Reprod. 2002 Jan; 17[1]:190-4. [DOI: 10.1093/ humrep/ 17.1.190].

11. Akdemir $Y$, Ayvaci $H$, Uludogan M. Effect of multiple thrombophilic gene mutations on uterine artery blood flow in nonpregnant recurrent pregnancy loss patients: are we searching enough? J Matern Fetal Neonatal Med. $2020 \mathrm{Jul}$; 33[14]:2466-2472. [DOI: 10.1080/14767058.2019.1569618].

12. Foo FL, Mahendru AA, Masini G, Fraser A, Cacciatore $S$, Maclntyre DA, et al. Association Between Prepregnancy Cardiovascular Function and Subsequent Preeclampsia or Fetal Growth Restriction. Hypertension. 2018 Aug; 72 [2]: 442450. [DOI: 10.1161/HYPERTENSIONAHA.118.11092]

13. Zhang K, Wang E, Li Y, Xu H, Zhang J, Wang X, Shu J. Role of low-molecular-weight heparin in altering uterine artery blood flow in recurrent spontaneous abortion: a prospective study. J Int Med Res. 2020 Aug; 48 [8]:300060520945558. [DOI: 10.1177/0300060520945558].

14. Elewa AM, Mansour AE, Gehad MA, Afify HEA. Ovarian reserve testing and uterine blood flow assessment using twodimensional and three-dimensional Doppler in patients with unexplained recurrent miscarriage. Benha Medical Journal 2017; 34[2]: 81-87. [DOI: 10.4103/bmfj.bmfj_107_17].

15. Dymara-Konopka W, Laskowska M. The Role of Nitric Oxide, ADMA, and Homocysteine in the Etiopathogenesis of Preeclampsia-Review. Int J Mol Sci. 2019 Jun 5; 20 [11]:2757. [DOI: 10.3390/ijms 20112757].

16. Azani A, Hosseinzadeh A, Azadkhah R, Zonouzi AAP, Zonouzi AP, Aftabi $Y$, et al. Association of endothelial nitric oxide synthase gene variants [-786 $\mathrm{T}>\mathrm{C}$, intron $4 \mathrm{~b} / \mathrm{a}$ VNTR and $894 \mathrm{G}>\mathrm{T}$ ] with idiopathic recurrent pregnancy loss: $A$ case-control study with haplotype and in silico analysis. Eur J Obstet Gynecol Reprod Biol. 2017; 215:93-100. [DOI: 10.1016/j.ejogrb. 2017.05.024].

17. Coates R, Cupples G, Scamell A, McCourt C. Women's experiences of induction of labour: Qualitative systematic review and thematic synthesis. Midwifery. 2019 Feb;69:17-28. [DOI: 10.1016/j.midw.2018. 10.013].

18. Mansour GM, Hussein SH, Abd El Hady RM, Mohammed HF, Abd El Gawad MM, Abou Gabal Al, Al-Awadhy RM, El Saied M. Uterine artery flow velocity waveform [FVW] type and subednometrial vascularity in recurrent pregnancy loss. J Matern Fetal Neonatal Med. 2020 Feb; 33[4]:527-532. [DOI: 10.1080/14767058.2018.1495190].

19. Yang W, Wu Z, Yu M, Peng X, Lu W, Feng W, Kang X. Characteristics of midluteal phase uterine artery hemodynamics in patients with recurrent pregnancy loss. J Obstet Gynaecol Res. 2019 Jul; 45[7]:1230-1235. [DOI: 10.1111/jog.13944]. 

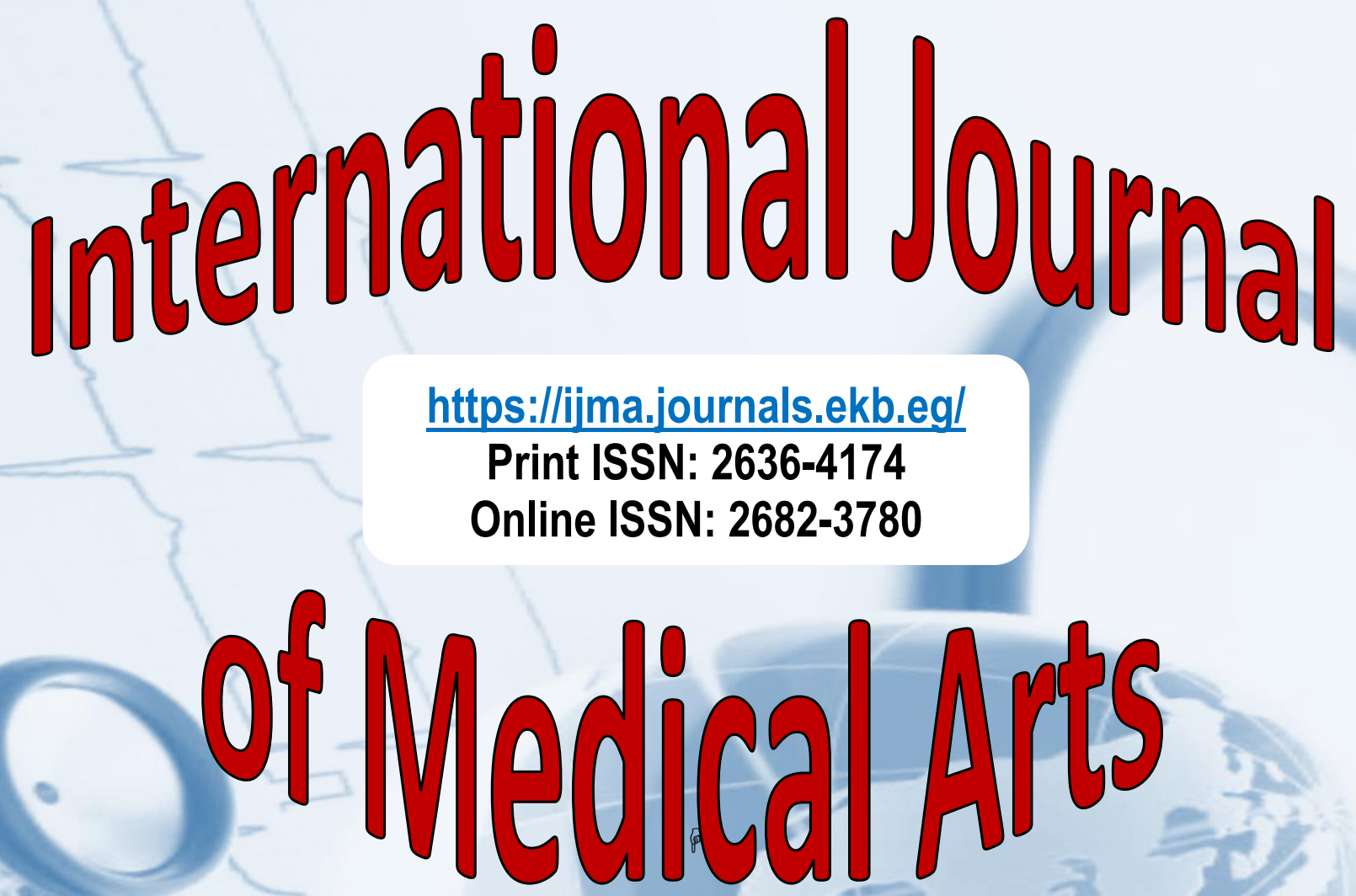